\title{
UN ÁNFORA ÁTICA PROCEDENTE DE LAS EXCAVACIONES DEL RECTORADO DE LA UNIVERSIDAD DE MÁLAGA
}

\section{AN ATTIC AMPHORA FROM THE EXCAVATIONS OF THE RECTORY OF THE UNIVERSITY OF MALAGA}

\author{
EDUARDO GARCÍA ALFONSO \\ Museo de Málaga. Plaza de la Aduana, s/n., E-29015, Málaga. Jefe del Departamento de Difusión \\ Correo-e: eduardom.garcia@juntadeandalucia.es. D https://orcid.org/0000-0001-6868-2659 \\ ResearcherID: <https://publons.com/researcher/AAN-8577-2020>
}

Resumen: La aparición de varios fragmentos de un ánfora ática de tipo SOS en las excavaciones (1998-2002) del antiguo edificio de Correos de Málaga (hoy Rectorado de la Universidad) resulta determinante para fechar la estructura muraria fenicia que se detectó en este lugar. Por su tipología, esta pieza griega puede encuadrarse en el tipo ático II de R. Docter, fechado en la segunda mitad del siglo VII a.C., dentro de su clasificación de estos recipientes anfóricos. En este sentido, el contexto de materiales fenicios aparecidos con esta pieza se encuadra muy bien en este horizonte cronológico. La presencia de este vaso en Málaga en momentos algo anteriores a la eclosión del comercio greco-oriental en el litoral andaluz plantea la cuestión de la temprana incorporación de la nueva ciudad al circuito distribuidor de productos griegos en Occidente, hasta entonces muy centralizado en Toscanos.

Palabras clave: Protohistoria, fenicios, griegos, cerámica, redes comerciales.

Los trabajos arqueológicos realizados entre 1998 y 2002 en la antigua Casa de Correos y Telégrafos de Málaga, con motivo de la transformación de este edificio en sede del Rectorado de la Universidad, documentaron una serie de estructuras y materiales arqueológicos de
Abstract: The appearance of several fragments of an Attic amphora of SOS type in the excavation (1998-2002) of the former main Post Office in Malaga (currently University Rectory Building) is decisive for the dating of the Phoenician wall structure that was detected in this place. For its typology, this Greek piece can be included in the Attic II class of R. Docter. The chronology is dated in the second half of the 7th century BC, within the classification of these vessels. In this sense, the context of Phoenician materials appeared with this piece is fixed very well on this chronological horizon. The presence of this container in Malaga, at a time slightly before the emergence of the East-Greek trade in the coastal Andalusia, raises the issue of the early incorporation of this new city to the distributor net of Greek products in the West, until this moment very centralized at the site of Toscanos.

Keywords: Protohistory, Phoenicians, Greeks, pottery, trade nets.

gran interés fechados en el periodo fenicio arcaico, con una compleja estratigrafía posterior que incluye fases de época romana, medieval y moderna (Chacón 1999: fig. 5, plano 2, Chacón y Salvago 2005: 25). Esta intervención ha permitido una primera aproximación a la 
topografía de un sector meridional de la ciudad fenicia en época arcaica, situado entre el declive suroeste de la colina de la Alcazaba y la antigua línea de costa (fig. 1). Aunque por la propia configuración del núcleo urbano, el área de la excavación podría considerarse a priori como un tanto marginal al mismo, la actividad arqueológica en el lugar aportó novedosas informaciones sobre el horizonte inmediatamente previo a la transformación de la Málaga fenicia en un centro de control territorial de primer orden en la costa mediterránea andaluza durante el siglo VI a.C. La revisión de dicha excavación, que se ha llevado a cabo en un número anterior de Spal, ha permitido una nueva valoración de los trabajos realizados en su momento, precisando su cronología de cara a la fundación de la ciudad, así como aportar propuestas para entender mejor este espacio en el contexto del asentamiento fenicio de Málaga (Suárez et al. 2020).

\section{EL CONTEXTO DEL ÁNFORA ÁTICA DEL RECTORADO}

Entre las cerámicas del siglo VII a.C. que se han recuperado en la citada excavación, hay que señalar la presencia de tres fragmentos de un ánfora ática, cuyo perfil corresponde al tipo SOS (Suárez et al. 2020: 4950, fig. 15, n. 40-42). Por desgracia se ha perdido la mayor parte del recipiente, aunque la forma es perfectamente restituible. Dichos fragmentos aparecieron en la UE09, la más profunda de toda la excavación, que se formó como el primer nivel de colmatación entre la roca pizarrosa -UE17- cortada artificialmente y la estructura denominada MR01. Entre ambas se formó un estrecho espacio hueco -FS11- que se rellenó con aportes terrígenos, en los cuales se individualizaron las UE09, 08 y 06. MR01 es un muro paralelo a la antigua línea de costa, en sentido ENE-WSW, construido mediante mampostería trabada con barro con cierto careo exterior, que alcanza $80 \mathrm{~cm}$ de anchura y que presenta su primera hilada avanzada respecto al resto del frente, a modo de zarpa-UE10- (fig. 2). A este muro se adosaban otros denominados MR02 y MR07. Todas estas estructuras de época fenicia arcaica fueron muy afectadas por la construcción de una serie de piletas de salazones romanas (Suárez et al. 2020: 42-48).

Aunque para el contexto arqueológico detallado del ánfora ática que nos ocupa y los materiales que la acompañan remitimos al reciente trabajo global sobre la actividad arqueológica en el Rectorado, es necesario insistir en que el referido muro MR01 y sus estructuras relacionadas parece que fueron el límite meridional del asentamiento fenicio en esta zona frontera con el mar abierto. En este sentido, se plantean las hipótesis de si corresponden a una línea de fortificación o forman parte de un sistema de aterrazamiento (Suárez et al. 2020: 72). La UE09 es un estrato de matriz arcillosa, que cae con fuerte buzamiento y que apoya en la roca natural cortada intencionadamente -UE17-, colmatando la zarpa del muro MR01 y parte inferior del alzado del mismo, claro indicio de que su formación fue inmediata a su construcción. Contiene materiales bastante homogéneos, mayoritariamente cerámicas fenicias y vasos a mano de tipología indígena en mucha menor medida, además de los tres fragmentos de ánfora ática referidos, todo ello mezclado con abundante carbón. Igualmente, hay una cierta presencia de malacofauna. Todos estos elementos nos hacen suponer que el origen de este relleno es antrópico y de procedencia doméstica, posiblemente de espacios ocupados situados a una cota más alta. La UE08, que cubre a la anterior, presenta un aspecto similar y cerámicas muy semejantes, aunque bastante menos carbón. Finalmente, la UE06 presenta escasa potencia y muy poco material. Rellenos más elevados con nulo o escaso material arqueológico colmatan totalmente el hueco FS11 entre la roca natural UE17 y el muro MR01, hasta el nivel construcción de la batería de piletas romanas situadas encima (Suárez et al. 2020: 46, fig.8).

\section{TIPOLOGÍA Y CLASIFICACIÓN}

La morfometría de los fragmentos conservados del ánfora ática del solar del Rectorado de la Universidad de Málaga nos permite reconstruir un recipiente que mide unos $70 \mathrm{~cm}$ de altura y un diámetro máximo de galbo de $55 \mathrm{~cm}$ aproximadamente. La boca presentaría un diámetro próximo a los $18 \mathrm{~cm}$ (fig. 3). El ánfora esta modelada en arcilla anaranjada oscura -color 49M del código de A. Cailleux-, con buena cocción oxidante, pero blanda, ya que se araña con facilidad. A nivel macroscópico, la pasta se presenta homogénea, sin apenas vacuolas, con algunos desgrasantes visibles. A la lupa binocular se observa que éstos son clastos pétreos. De visu son compatibles con hematites, que han sufrido un proceso parcial de rubefacción durante la cocción $\mathrm{y}$ han adoptado un color rojizo oscuro producto de la oxidación (figs. 4-5). Aunque no hemos realizado un análisis petrográfico, las características de la pasta son totalmente compatibles con las producciones áticas anteriores al siglo VI a.C., pero la atribución a este taller concreto se ha efectuado teniendo en cuenta, además, 


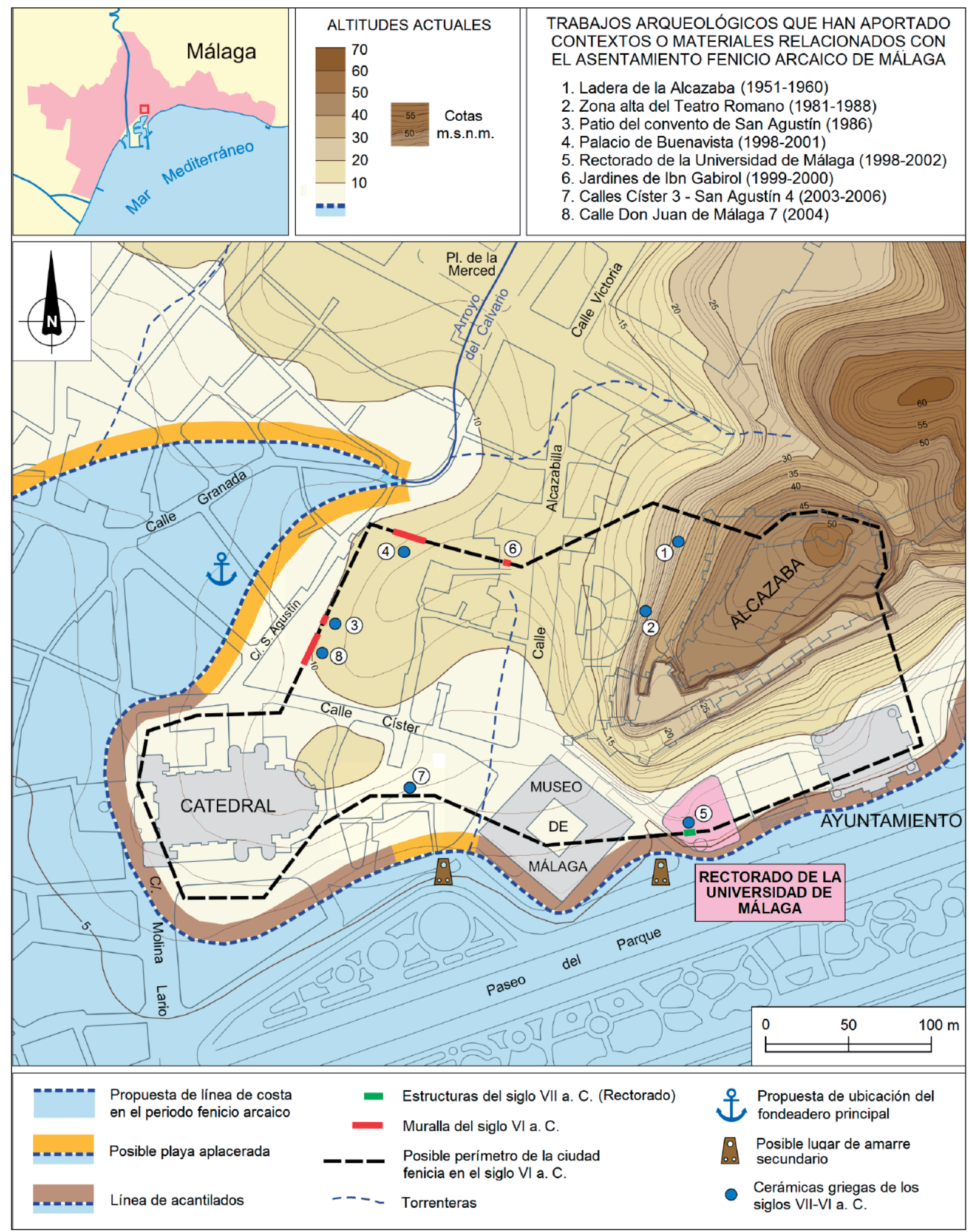

Figura 1. Ubicación del solar del Rectorado de la Universidad en el contexto de la Málaga fenicia de los siglos VII-VI a.C. 
UE17. Roca natural

FS11. Recorte de la roca natural

UE10. Zarpa del muro MR01

MR01. Muro fenicio en sentido NE-SO

UE09. Primer nivel de relleno de FS11

UE08. Segundo nivel de relleno de FS11

UE 06. Tercer nivel de relleno de FS11
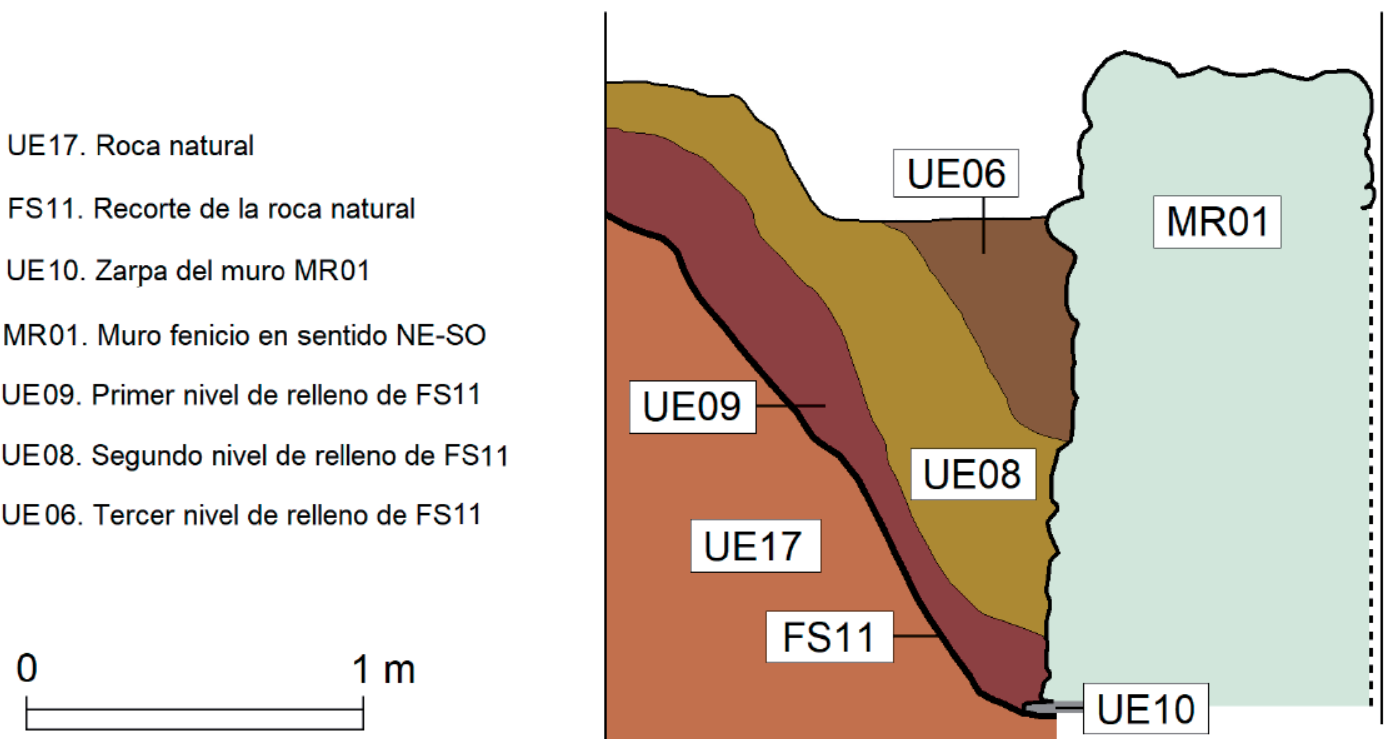

Figura 2. Solar del Rectorado de la Universidad de Málaga. Estratigrafía del periodo fenicio (según Suárez et al. 2020).

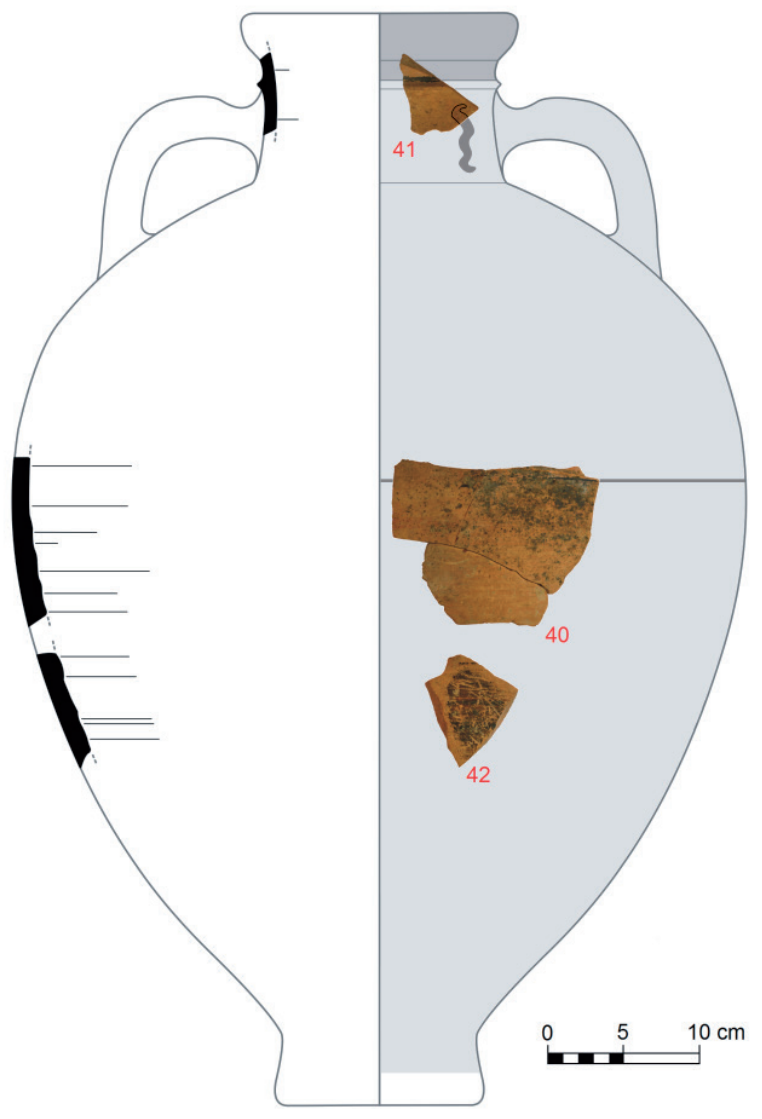

Figura 3. Solar del Rectorado de la Universidad de Málaga Ánfora ática tipo SOS: fragmentos y restitución. diversos factores, tales como los detalles de forma, decoración y tratamiento de su superficie, así como por comparativa con otros fragmentos de ánforas áticas de este periodo. No obstante, como señala I. K. Whitbread (1995: 366-367) la observación puramente óptica de la pasta adolece siempre un considerable grado de subjetividad.

El tratamiento de la superficie del ánfora presenta rasgos que muestran un cierto cuidado. Al ligero alisado de la misma, hay que añadir una primera aplicación de un engobe muy liviano de una tonalidad marrón oscura, que sería una disolución acuosa muy diluida. El artesano utilizó una brocha, siguiendo una traza horizontal, en paralelo a las líneas de torneado. A continuación se aplicaron una o dos capas más de este engobe, de manera que su tonalidad se fue oscureciendo y su grosor aumentando, aunque no llegó cubrirse toda la superficie de una manera uniforme. Así, lo encontramos aplicado en la zona exterior del cuello, por encima del baquetón típico de esta forma cerámica, desde donde llegaría hasta el remate superior del labio, hoy perdido. Es una característica muy propia de las ánforas SOS, ya que la parte inferior del cuello lleva una zona en reserva donde se colocan los típicos motivos que dan nombre a estas producciones (fig. 6). En lo poco conservado del galbo se observan tres tenues líneas paralelas horizontales donde el engobe es más denso, dos de las cuales están agrupadas. En ellas, el engobe ha sido aplicado siguiendo las líneas de torneado del recipiente, mediante un pincel algo más fino. La aplicación de estas 


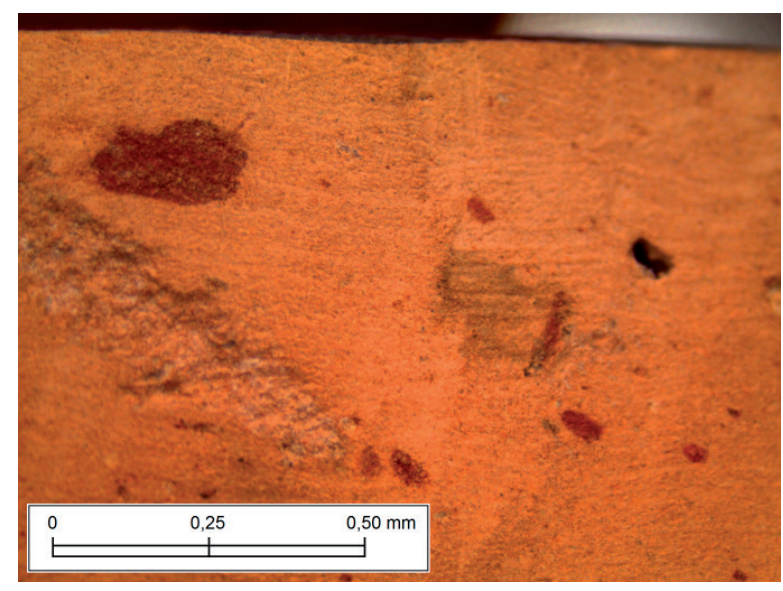

Figura 4. Ánfora ática del Rectorado. Detalles del núcleo interno y engobe de la superficie exterior observados con la lupa binocular (fotografía: Francisco Martínez Sevilla).

diferentes capas debió hacerse en horizontal, mientras que la pieza giraba en el torno, pero seguramente no en el mismo momento, sino intercalando alguna sesión de secado entre ellas. Esta característica es propia de las ánforas SOS áticas y es perfectamente observable en piezas con buena conservación y queda bien individualizada en el fragmento n. ${ }^{\circ} 41$. En principio, estas aparentes franjas no deben confundirse con ningún tipo de decoración. Por otra parte, estas piezas suelen llevar una banda ornamental en la zona alta del galbo, debajo de las asas, formada por varias líneas horizontales de engobe oscuro dispuestas sobre una zona en reserva. Es posible que un resto de este tipo de composición quede en la zona superior del fragmento $n .^{\circ} 40$, donde se aprecia un estrecho filete de engobe especialmente intenso. Por todo ello, es muy posible que originalmente el color de la superficie de este recipiente fuese de un tono cercano al negro, como en la mayoría de los ejemplares, el cual se ha degradado a su aspecto actual hasta casi desaparecer en buena parte debido tanto a las condiciones físico-químicas del sustrato de depósito como al propio procedimiento de fabricación. En cualquier caso, a pesar de su mala conservación, la aplicación del engobe superficial en el ánfora del Rectorado de la Universidad de Málaga es muy diferente a la manera irregular, dispersa y rápida característica de las piezas à la brosse, que fueron las sucesoras del tipo SOS.

En el fragmento n. $^{\circ} 41$ podemos observar por encima del baquetón una zona que conserva el engobe oscuro con cierta densidad, que seguramente se prolongaría a todo el labio, como es característico en estas ánforas. Bajo el baquetón queda una zona de reserva, en la

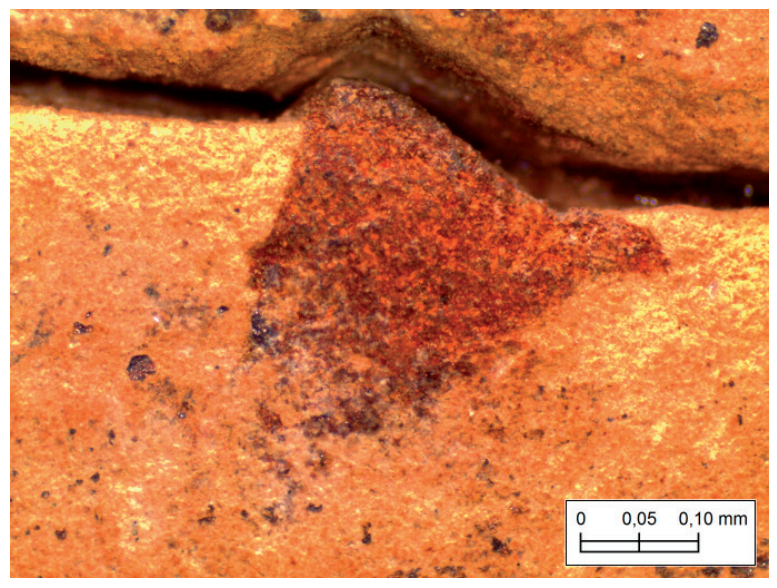

Figura 5. Ánfora ática del Rectorado. Clasto macroscópico de hematites oxidado y con zonas rubefactadas observado con la lupa binocular (fotografía: Francisco Martínez Sevilla).

que se aprecia, aunque de forma muy tenue al estar muy perdido, el arranque de un motivo en forma de sigma, uno de los que da origen a la denominación ánforas de tipo SOS (fig. 7). Esta decoración tan característica y el tratamiento un tanto cuidado de la superficie, pese a la importante pérdida de engobe por una deficiente conservación de la pieza, nos indican de manera clara que estamos ante un recipiente de esta tipología (Johnston y Jones 1978, Pratt 2015). La distinción entre las ánforas SOS y sus inmediatas sucesoras à la brosse no es sencilla cuando estamos ante un ejemplar fragmentario y mal conservado, si bien en este caso no hay dudas en clasificarlo dentro del primero de los tipos citados.

\section{CRONOLOGÍA}

El trabajo clásico de A. Johnston y R. D. Jones (1978: 103) sobre las ánforas SOS abordó también algunos aspectos de su evolución, estableciendo una clasificación entre el tipo antiguo (725-675 a.C.), medio (675-625 a.C.) y tardio (625-575 a.C.), pero con una caracterización bastante laxa. A este respecto, el artículo de C. E. Pratt (2015: 214-215), partiendo de una aportación anterior de M. A. Rizzo (1990), ha dividido las ánforas SOS en dos grupos: antiguo y tardío, al tiempo que ha realizado una completa síntesis de su dispersión mediterránea. Sin embargo consideramos que la propuesta que realizó R. F. Docter (1997: 236-237) en su tesis doctoral sobre las ánforas áticas de Toscanos y Cartago es la más detallada, al centrarse pormenorizadamente en estos dos centros. 


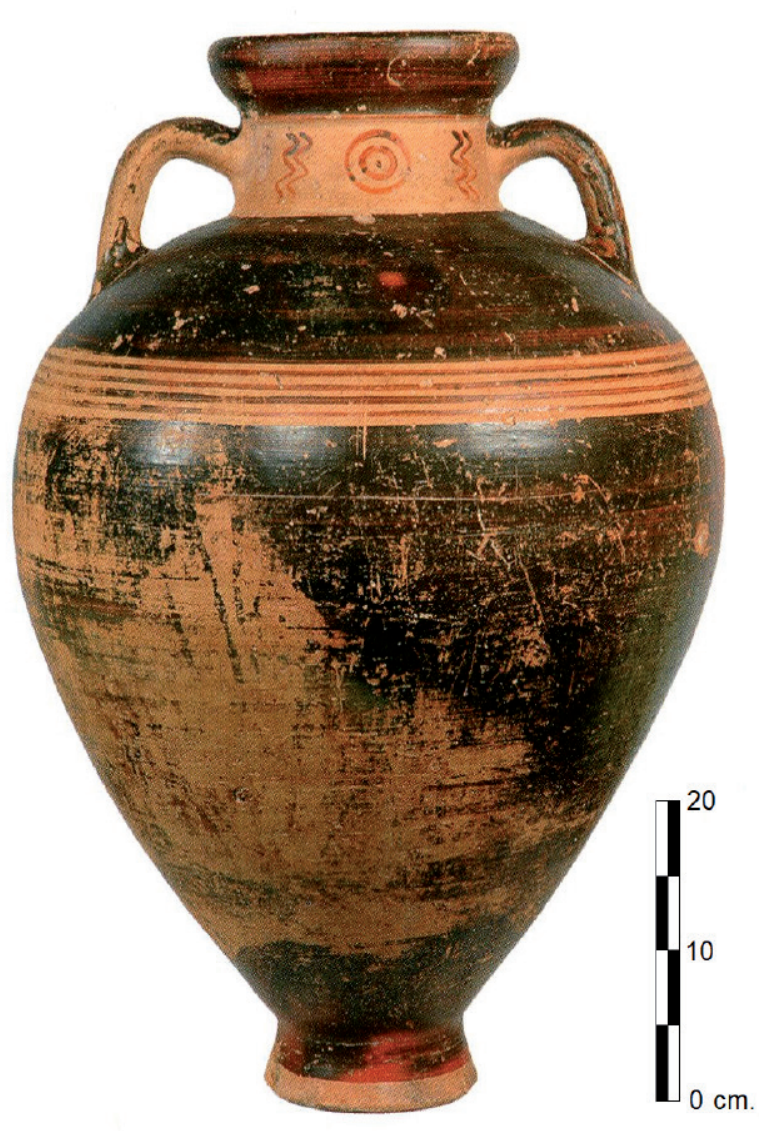

Figura 6. Cerveteri. Necrópolis de Monte Abatone, tumba 4. Ánfora ática de tipo SOS (675-625 a. C.), altura: $71 \mathrm{~cm}$. Museo Nazionale Archeologico Cerite, Cerveteri. (Ciuccarelli, 2013: 116 y 119, n. 82).

Docter determina la existencia de tres categorías en estos recipientes, que él identifica como los tipos ático I, ático II y ático III (fig. 8). Aunque estas categorías plantean también un sistema tripartito, tienen dataciones ligeramente diferentes a las establecidas por Johnston y Jones, además de ampliar en su conjunto el lapso temporal de uso de estos recipientes. De este modo, la producción de ánforas SOS arrancaría a mediados del siglo VIII a.C. con el tipo ático I, que se desarrollaría hasta c. 650 a.C.; el ático II se produjo entre mediados y finales del siglo VII; para terminar, el ático III correspondería a los últimos momentos del siglo VII y primera mitad del VI a.C., momento en que estas piezas fueron siendo progresivamente sustituidas por los ejemplares à la brosse, con la aplicación del barniz superficial de forma mucho más rápida y descuidada, pero sin cambios tipológicos destacables.
A pesar de la escasa superficie conservada, consideramos que el ánfora SOS aparecida en el Rectorado de la Universidad de Málaga presenta algunos rasgos que permiten incluirla en el tipo ático II de Docter. Por un lado, la aplicación del engobe con cierta rapidez, ya comentada, contrasta con la gran adherencia, decoración cuidada e intenso color negro y uniforme que muestran los ejemplares SOS más antiguos, encuadrados en el tipo ático I. Por ello, este mismo tratamiento superficial todavía con cierto esmero, diferente del que vemos en las piezas à la brosse, lo conservarán las ánforas SOS hasta el final de su producción, incluso en el tipo ático III, aunque cada vez acercándose más a sus sucesoras. La conservación de parte del cuello nos permite observar algunas de los elementos formales propios del tipo ático II en esta pieza. Así, la presencia del estrecho baquetón desde el cual se inicia el engrosamiento exterior del labio, hoy perdido, resulta determinante para su clasificación. Esto permite apreciar el exvasamiento del cuello en el ejemplar del Rectorado, que en las producciones anteriores es cilíndrico y muestran el baquetón mucho más abajo del labio, mientras, en el tipo ático III sencillamente esta moldura desaparece. Por ello, esta ánfora SOS ática se fecharía en la segunda mitad del siglo VII a.C., sin alcanzar, en principio, los momentos finales de dicha centuria, lo que está en consonancia con el resto del material aparecido en la UE.09, donde apareció la pieza, así como la contigua UE.08, de la excavación del solar del Rectorado de la Universidad de Málaga (Suárez et al. 2020: 48-63, figs. 12-16). Usando la cronología propuesta por Johnston y Jones (1978: 103), la pieza estaría englobada dentro de su tipo medio, que se dataría entre 675-625 a.C., fechas que no resultan excesivamente discordantes con lo anterior. Por ello, una fecha centrada en los años posteriores a mediados del siglo VII a.C. sería perfectamente aceptable y bien conectada con el resto del registro arqueológico obtenido.

Por otro lado la aparición de los tres fragmentos de una misma pieza en la UE09, con alguno de tamaño considerable -como el n. 40- y con pocas señales de rodamiento indica que su deposición no se produjo como consecuencia de un arrastre erosivo. Esta ultima característica resulta también observable en los materiales procedentes de la UE.09 y UE.08 de la excavación (Suárez et al. 2020: 45 y 48), por lo que cabría plantear la hipótesis de que el estrecho espacio denominado FS.11, generado entre la roca natural del cerro cortada ex profeso -UE.17- y el muro MR.01, fue rellenado intencionadamente nada más acabado de construirse este último, con materiales terrígenos y desechos 


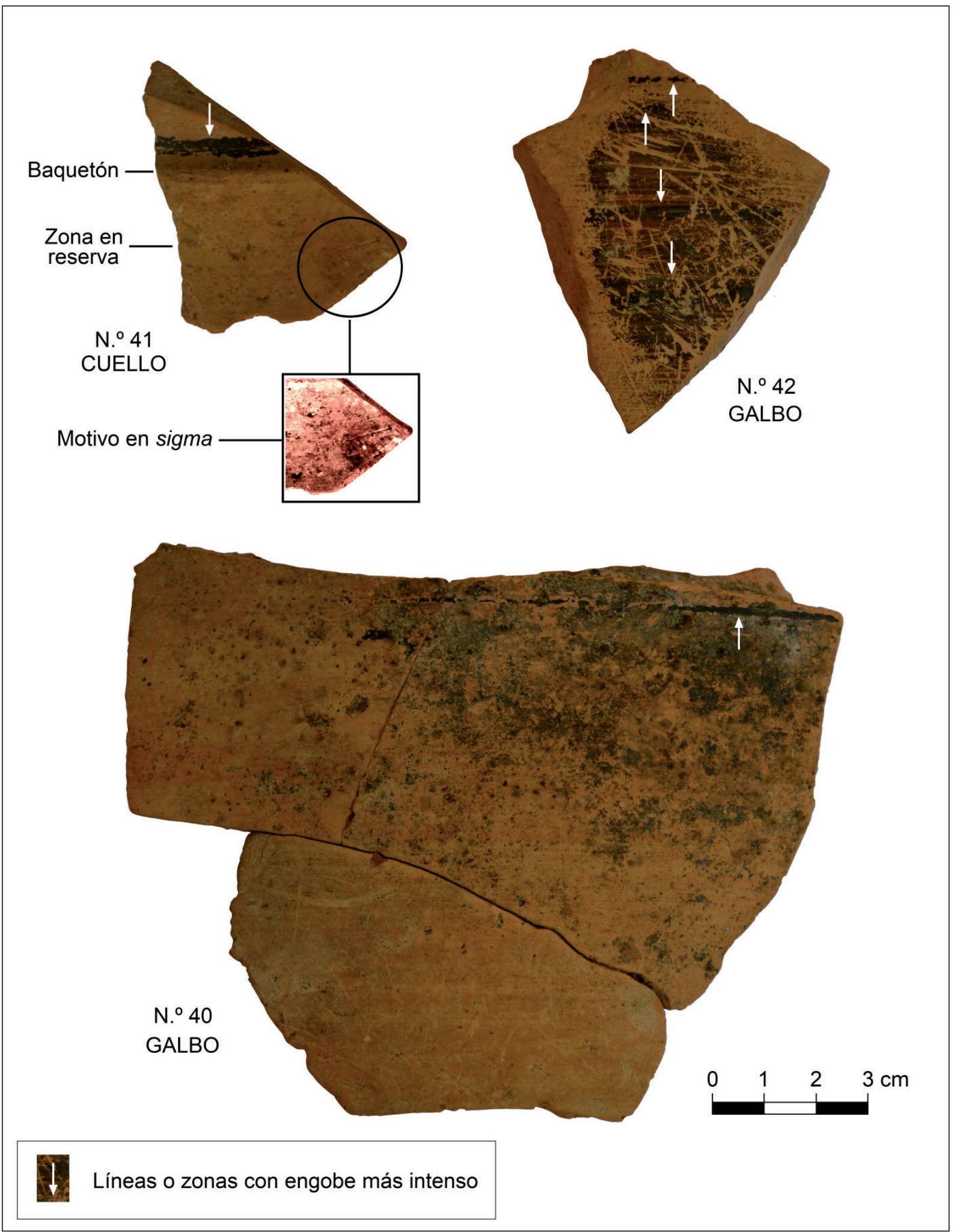

Figura 7. Ánfora ática del Rectorado. Tratamiento superficial. N. ${ }^{\circ} 41$ con detalle del motivo en sigma procesado con filtro de color para su mejor visualización. 


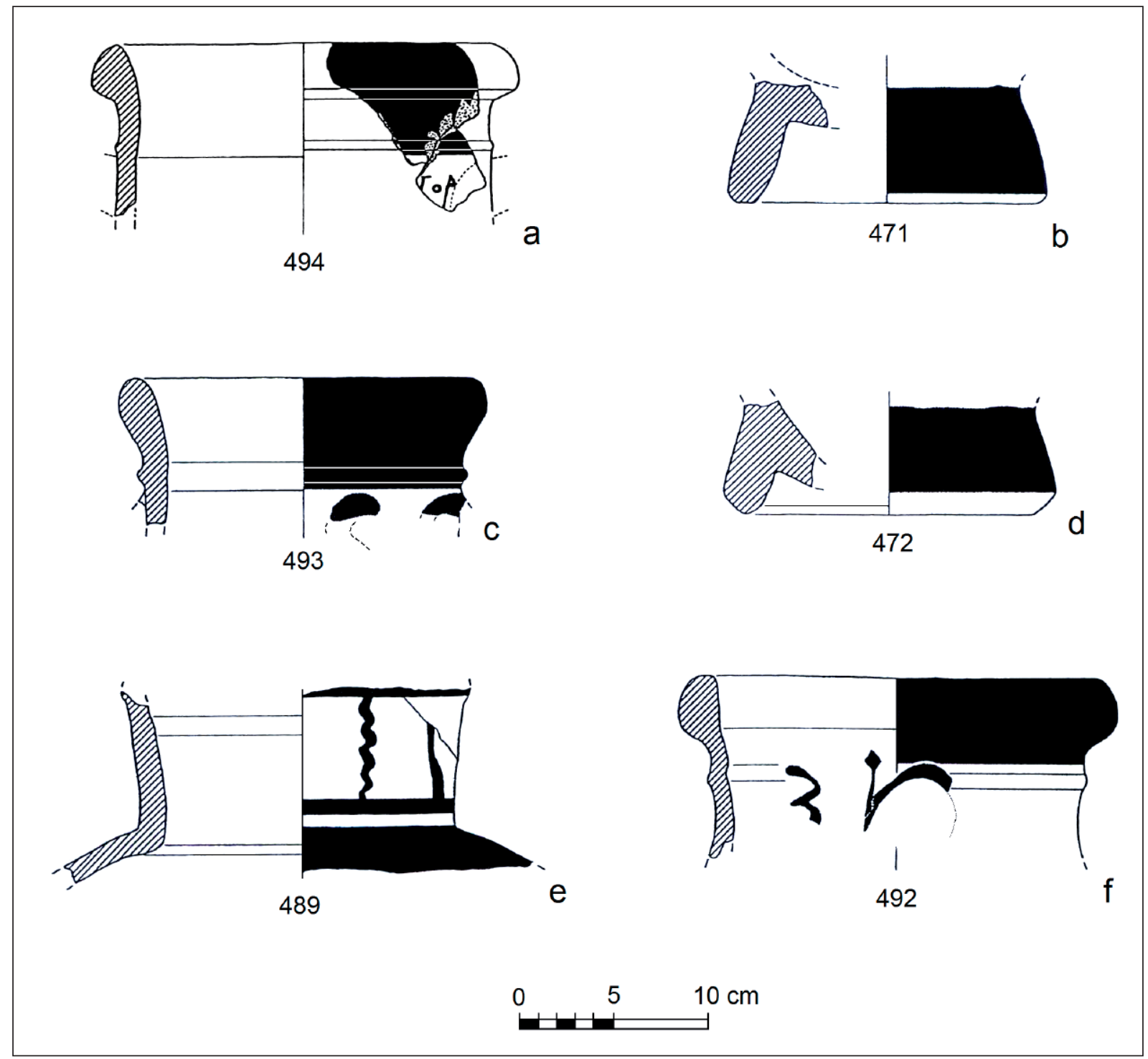

Figura 8. Toscanos. Ánforas áticas de tipo SOS (dibujos y números según Docter, 1997). a) Área del edificio C. Estrato IV a-b. Tipo ático I; b) Área del edificio C. Estrato IV. Tipo ático I; c) Foso. Estrato 3c ó 3b. Tipo ático I ó II; d) Área del edificio CEstrato IV a-b. Tipo ático I ó II; e) Foso. Estrato 3. Tipo ático I ó II; f) Foso. Estrato 5. Tipo ático II.

domésticos del entorno próximo. Por ello, la datación de esta estructura MR.01 y sus muros adyacentes documentados en el solar del Rectorado de la Universidad de Málaga debe ser coetánea a esta ánfora o muy poco posterior, planteando una cronología entre mediados y finales del siglo VII a.C. Gracias a Toscanos (García Alfonso 2015: 144) y La Fonteta (García Martín 2011: 536-537 y 541), sabemos que este tipo de piezas de importación eran amortizadas muy rápidamente al transvasar sus contenidos a otros envases más pequeños, dado que solo aparecen en los puertos de llegada del sur de Iberia, por lo que su periodo de vida útil más allá de la travesía marítima era muy corto.

\section{ANFORAS ÁTICAS ARCAICAS EN OCCIDENTE. FUNCIÓN Y EVOLUCIÓN COMERCIAL}

Desde muy pronto se puso de manifiesto que las ánforas de tipo SOS tenían una gran dispersión en todo el ámbito mediterráneo, testimonio de la pujanza del 
comercio exterior ateniense, especialmente de su producción oleícola. Aunque algunos autores plantearon hace ya tiempo que este tipo de recipientes contuvo fundamentalmente vino (Niemeyer 1985: 31), la mayoría de los autores se han decantado desde el trabajo de Johnston y Jones (1978: 140) por señalar al aceite de oliva como el producto generalmente envasado en las ánforas tipo SOS, dando lugar a una bibliografía amplia que ha recogido en un trabajo relativamente reciente $C$. E. Pratt (2015: 240-245). El aceite es una materia prima de la que existió un importante déficit en el Mediterráneo occidental durante el periodo fenicio arcaico. La introducción del olivo cultivado (Olea europaea europaea) en la Península fue un proceso lento y no se ha constatado la presencia de oleicultura de manera segura hasta el siglo IV a.C., ya que por el momento es imposible determinar si los restos de Olea procedentes de las excavaciones corresponden a variedades silvestres o cultivadas (Buxó 1997: 284-286, Buxó y Piqué 2008: 163-164, Pardo 2015: 172). El aceite de oliva era imprescindible para numerosos usos y procesos productivos propios del mundo fenicio, herederos de una tradición milenaria en Siria-Palestina. Por ello, ante el posible déficit, debido a la escasa productividad de las especies de Olea silvestres que existían en el Mediterráneo occidental a la llegada de los fenicios, dichas necesidades pudieron ser cubiertas en buena medida mediante importaciones (Martín Ruiz 2013: 124125, García Alfonso 2015: 137-140). Estamos ante un producto con una fuerte demanda en todo el Mediterráneo y Próximo Oriente. En este sentido existen evidencias del incremento de la producción en los siglos VIII y VII a.C. en lugares como Eqron -Filistea-, destinada al consumo de los núcleos centrales del Imperio Neoasirio (Eitam 1996: 183, Gitin 1998: 173). Coetáneamente, fuera del área de influencia de los grandes estados orientales, la mayor producción de aceite se localizaba en el mundo griego, sobre todo en Atenas, Corinto (Koehler 1981: 452, Whitbread 1995: 257) y algunos núcleos de la Grecia del Este (Cook y Dupont 1998: 167, Jatsisavvas 2008: 53-54, Koparal et al. 2010). Ello explicaría la afluencia de ánforas de este origen al Mediterráneo occidental como contenedores de este aceite importado.

Otra cuestión es el origen de los transportistas que movieron esta mercancía, que debió ser cambiante con el paso del tiempo. Descartado el interés de los propios atenienses en el comercio marítimo en estos momentos, los protagonistas más antiguos del circuito primario de distribución, en la segunda mitad del siglo VIII a.C., fueron posiblemente los eubeos, como confirma la importante presencia de estos recipientes en Pitecusa (Di Sandro 1986: 15-22, Pratt 2015: 238, n. 111). Cuando la pujanza comercial euboica empezó a decaer, a lo largo del siglo VII a.C. la primacía de este comercio debió pasar a los eginetas y a los corintios, rivales entre sí, pero aliados cada uno por su cuenta de los atenienses. Desde nodos como Chipre, Rodas, Creta y Sicilia, este tráfico sería introducido en las redes marítimas fenicias (García Alfonso 2015: 150-151, 2018a: 455). Finalmente, es seguro que a lo largo de la primera mitad del siglo VI a.C. el ánfora de tipo SOS comenzara a utilizarse también para envasar vino, como parece dejar clara la imagen de Dioniso portando uno de estos recipientes en el Vaso François, hacia 570-560 a.C., en un momento en que la producción de esta forma ya estaba en franca decadencia (Torelli 2007: 37 y 101).

En Iberia tenemos ejemplares de ánforas de tipo SOS desde la segunda mitad del siglo VIII a.C. o, como muy tarde, desde el último tercio de esa centuria (fig. 9). La pieza más antigua procede del Castillo de Doña Blanca; se trata de un recipiente ático que está acompañado de un ánfora de taller corintio (Cabrera 1994a: 25, 1995: 389). Más tardía, ya de finales del siglo VIII e inicios del siguiente, es el ánfora griega prácticamente completa documentada en el estrato $\mathrm{V}$ del corte 5 del Cerro del Villar. Presenta su superficie cubierta con barniz negro muy perdido y un perfil muy similar a las ánforas SOS del tipo ático I. Sin embargo, su atribución a un taller concreto ha sido muy discutida, apuntándose las posibilidades de Calcis (Cabrera 1994b: 102), Italia (Cabrera 2003: 66) o las islas del Egeo (Vegas 1999: 136). Para Docter (2001: 71) esta ánfora podría vincularse a otros fragmentos con barniz negro documentados en Toscanos, que este investigador holandés ha atribuido a la Grecia del Este.

Aunque las ánforas SOS áticas y sus imitaciones comenzaron a llegar al Mediterráneo central y occidental desde mediados del siglo VIII a.C., su eclosión se produjo en el siglo VII a.C. En estos momentos, podemos observar su concentración en determinados lugares, donde se encuentra una cantidad considerable de ejemplares, combinada con su dispersión en otros centros donde aparecen en muy pequeño número. Aunque podemos tener una visión distorsionada debido a la propia dinámica de la investigación arqueológica en estos lugares, planteamos la hipótesis de que este comercio, fundamentalmente de aceite, funcionaba mediante la conexión marítima entre las áreas de producción, tanto el Ática como otras zonas, y una serie de centros portuarios, donde el producto se almacenaba y se trasvasaba a otros recipientes para su distribución. Ello 


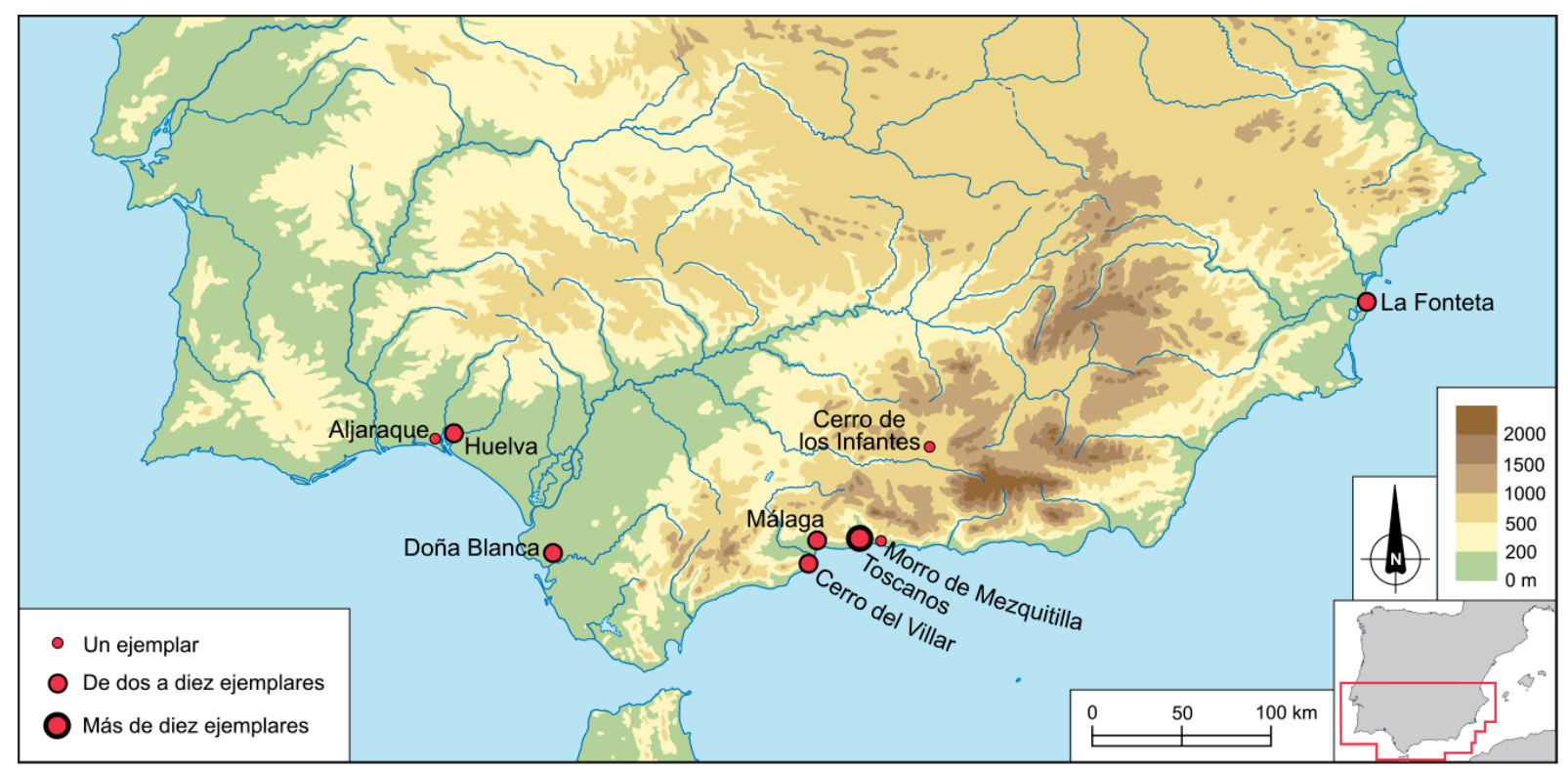

Figura 9. Dispersión de las ánforas áticas de tipo SOS y à la brosse en la Península Ibérica.

explicaría la concentración de ánforas SOS en unos pocos enclaves griegos de Sicilia y sur de Italia, como Mégara Hiblea (Albanese 1996: 99-102), Camarina (Sourisseau 2006: 132) o Incoronata (Bron 2011: 472477;), entre otros, que actuarían como nodos de conexión con el mundo indígena, donde estos recipientes son extraordinariamente escasos. Igualmente encontramos un conjunto de 18 ánforas áticas en Cartago entre c. 750 y 480 a.C. (Docter 2000: fig. 6).

En Iberia la mayor concentración de ánforas áticas de tipo SOS que conocemos hasta el momento la encontramos en Toscanos. En este asentamiento de la desembocadura del río de Vélez, entre c. 685 y c. 620 a.C., se ha documentado un número mínimo de individuos (NMI) de 26 ejemplares, que constituyen el $28.5 \%$ de todas las ánforas griegas del enclave para ese mismo lapso cronológico, para disminuir hasta un $16.8 \%$ a partir de c. 620 a.C. hasta el abandono del establecimiento (Docter 2000: fig. 7). Desde la segunda mitad del siglo VIII hasta finales del VI a.C., no faltan hallazgos de ánforas áticas en otros asentamientos fenicios arcaicos de la Península, pero se trata de ejemplares escasos y dispersos. Son los casos de la bahía de Málaga (Cerro del Villar y la propia ciudad de Málaga) -ver más adelante-, Morro de Mezquitilla (Schubart 1984: lám. 3-c), Huelva (Cabrera 1989: 64 y 72-73), Aljaraque (Domínguez Monedero y Sánchez 2001: 5), Doña Blanca (Domínguez Monedero y Sánchez 2001: 19) o La Fonteta (Gailledrat y Rouillard 2007: 230-231, Rouillard 2007: 190, fig. 201, n. 3;
García Martín 2011: 536-537). Por el contrario, en el interior peninsular solo tenemos noticias de la aparición de un ejemplar en el Cerro de los Infantes, en plena Vega de Granada (Niemeyer 1980: 287, nt. 31). Igualmente se conocen algunos ejemplares áticos de tipo SOS y/o à la brosse en lugares muy vinculados a la Península por la navegación y el comercio fenicio, como el fragmento procedente del bastión de Santa Lucía en la ciudad de Ibiza (Ramon 1983: 111-113, fig. 1.1, Rouillard 1991: ficha 886) o el conjunto formado al menos por 12 piezas documentado en el islote de Mogador, en la costa atlántica marroquí (López Pardo y Mederos 2008: 262-266).

La fundación de Toscanos se situaría c. 730-720 a.C. según la cronología tradicional cerámica. Desde los primeros años el enclave recibió importaciones de ánforas griegas de talleres como Corinto y Grecia del Este. Las ánforas áticas comienzan a llegar a partir de c. 685 a.C., fecha que para R. Docter (1997: 60 y 63) coincide con la construcción del edificio $\mathrm{C}$, considerado un almacén de mercancías y que da inicio a la fase Toscanos III. Esta datación rebaja unos años la atribuida por H. G. Niemeyer (1986: 113) y M. E. Aubet (2009: 320-321), que la sitúan c. 700 a.C. La evolución del comercio de ánforas griegas en Toscanos tiene que ser abordada desde los datos publicados por Docter (1997: 57-68, 233-243; 2000), que recoge los materiales hallados a lo largo de las campañas realizadas entre 1964 y 1978, por desgracia sin ningún ejemplar completo. En síntesis, para este investigador el lapso cronológico 
entre 685 y 620 a.C. corresponde al periodo de máxima afluencia de ánforas griegas al enclave. De estas importaciones, el mayor número de ejemplares procede de la costa de Asia Menor e islas próximas, con talleres como Quíos, Samos y Clazómenas, aunque a la mayoría de estas piezas greco-orientales no ha podido asignarse una procedencia concreta. Las ánforas samias parecen vincularse con seguridad al aceite, mientras que las del resto de los talleres greco-orientales pueden contener tanto aceite como vino. Tras este grupo heterogéneo de la Grecia del Este, las ánforas áticas de tipo SOS son las más documentadas en Toscanos, siendo Atenas realmente el centro productor más representado -con el $28.5 \%$ en el periodo señalado-, aunque superado en conjunto por los talleres greco-orientales, si agrupamos estos últimos. A partir de c. 620 a.C. el número de ánforas griegas en el asentamiento disminuye rápidamente hasta el abandono final del mismo c. 550 a.C., con un 16.6\% de ejemplares áticos (fig. 10). Esto es síntoma de que, posiblemente, en los momentos de finales del siglo VII una parte importante de este comercio pudo desviarse a Málaga, ahora convertida en un centro emergente frente a los asentamientos de fundación más antigua, como Toscanos y el Cerro del Villar, aunque lógicamente estos materiales continuaron llegando a estos lugares prácticamente hasta su abandono (Cabrera 1994b: 108, Docter 2000: 68, fig. 7).

A partir de los inicios del siglo VI a.C. las importaciones de aceite ateniense y greco-oriental disminuyeron bruscamente en el Mediterráneo central y occidental. En algunos mercados como Etruria la disminución de ánforas áticas a lo largo de toda la centuria supera el 50\% respecto al siglo anterior (Gras 1987: 46). En Cartago y en Toscanos el descenso en estas importaciones es todavía más intenso, en torno al $80 \%$ (Docter 2000: figs. 6-7). Mientras, en Huelva y la bahía de Málaga, al no tener apenas datos para el siglo VII, no podemos hacer una valoración de cómo evolucionó este comercio, pero es difícil que escapase a la tendencia generalizada a la disminución que observamos en todo el mundo fenicio occidental. El caso de Ampurias resulta significativo, ya que la presencia de ánforas áticas SOS y à la brosse es nula por el momento, aunque de estas últimas sí hay ejemplares de la Grecia del Este o incluso greco-occidentales en la Neápolis (Miró 1989: 39, Domínguez Monedero y Sánchez 2001: 64). Tampoco aparecen en la Palaiápolis emporitana, ubicada en Sant Martí d'Empúries, que sí ha proporcionado producciones griegas de estos mismos talleres. Esto permite inferir que el comercio de ánforas áticas entró en decadencia antes de la consolidación de la presencia focea

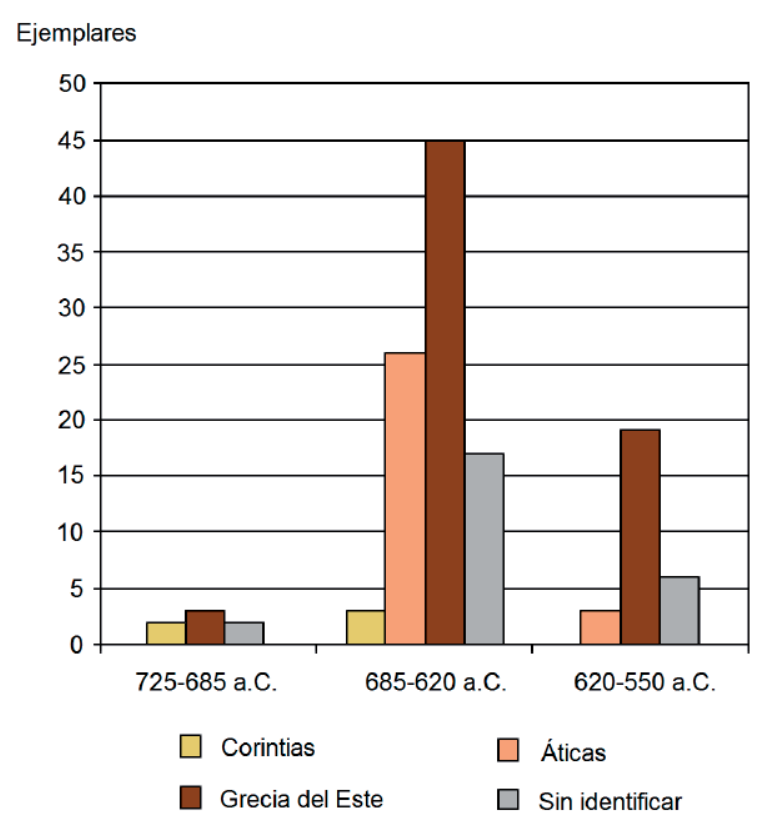

Figura 10. Evolución de las importaciones de ánforas griegas en Toscanos (según Docter, 2000).

en el golfo de Rosas -fase III de Sant Martí iniciada c. 580 a.C. (Castanyer et al. 1999: 271-277 y 282-285, Aquilué et al. 2000: 289-290 y 293)-, pero se mantuvo unos pocos años más de manera residual en los consolidados mercados fenicios del sur peninsular.

Las causas de esta caída de las importaciones áticas debieron ser múltiples y complejas. Pudieron coincidir razones internas de la propia Atenas, como las derivadas de las reformas introducidas por Solón en 594-593 a.C. en la política económica, agraria y comercial, o bien una crisis del olivar ático (Domínguez Monedero 2001: 82-83), circunstancias que pudieron tener su equivalencia en otros estados proveedores y en sus relaciones externas. Igualmente, pudo haber cambios en las redes de comercialización a larga distancia que veían el final del modelo de intercambio empórico típico del periodo arcaico (Domínguez Monedero 2000: 37-39), así como la posible entrada en escena de nuevos centros suministradores, especialmente en el Mediterráneo central y en la propia Iberia.

\section{EL ÁNFORA ÁTICA DEL RECTORADO Y LA MÁLAGA FENICIA}

Esta ánfora SOS del Rectorado nos permite apuntar de manera firme una de las fechas más antiguas 
proporcionadas por el asentamiento fenicio de Málaga, dada su inclusión en el tipo ático II, que corresponde a la segunda mitad del siglo VII a.C. En esto se muestra coincidente cronológicamente con el resto de materiales aportados por la excavación del solar (Suárez et al. 2020: 71-72). Por lo que sabemos actualmente, estos momentos corresponden a la instalación de los primeros contingentes fenicios en el área identificada a nivel geomorfológico como promontorio de la Catedral, ubicado al oeste de la colina de la Alcazaba, en cuyo flanco sur estaría incluido el espacio que actualmente ocupa el Rectorado de la Universidad de Málaga. En este sentido, las excavaciones del palacio de Buenavista y del solar de calle Císter 3 - San Agustín 4 han aportado una serie de datos que avalan una primera presencia fenicia en esta zona baja de la ciudad en momentos del siglo VII a.C., asentándose directamente sobre el nivel geológico (Arancibia y Escalante 2010: 3638, Escalante et al. 2012: 87).

Hasta ahora, la presencia de material griego en Málaga durante esta etapa inicial consistía únicamente en un fragmento de dino de producción quiota aparecido en las excavaciones del palacio de Buenavista (Arancibia y Escalante 2006: 46, fig. 7). Es pieza cercana al estilo tardío de la Cabra Salvaje, pero con las características formales del Grand Style de esa isla (Lemos 1991: 94-118; Cook y Dupont 1998: 71-73), el cual presenta una fecha de inicio de producción que no remontaría -en principio- más allá de 600 a.C. en su centro de producción, por lo que vendría a poner el límite cronológico final a esta fase (García Alfonso 2018b: 32-33). Pese a su escasa representación, esta presencia de productos griegos en un asentamiento fenicio como Málaga, de reciente fundación y posiblemente creado como una prolongación de las actividades metalúrgicas del Cerro del Villar, pensamos que tiene su relevancia, pues muestra un cambio en el patrón de los circuitos comerciales. Por lo que sabemos, durante buena parte del siglo VII a.C. el principal centro receptor de productos griegos de todo el sur peninsular debió ser Toscanos, incluso más que centros como Huelva, que nos resulta bastante desconocida para este periodo en lo que respecta a su área de asentamiento y apenas ha aportado materiales griegos coetáneos, lo que contrastará con la primera mitad del siglo siguiente (Cabrera 1989: 48). En la misma costa malagueña, Toscanos contrasta con el Cerro del Villar. En este segundo enclave de la desembocadura del Guadalhorce solo se han documentado con seguridad dos fragmentos de cerámica griega fechados en el siglo VII (Cabrera 1994b: 103), lo que iguala al número de los aparecidos en la propia Málaga en esta misma centuria por el momento. Dado que el cercano Cerro del Villar vivió durante este periodo su momento de máximo auge, como centro comercial y seguramente administrativo, queda claro que el rol de principal puerto terminal para la llegada de productos griegos correspondía a Toscanos y no al Cerro del Villar.

Esta situación cambió radicalmente en el siglo VI a.C., cuando este papel fue asumido en la costa mediterránea andaluza por Málaga, que adquiere el carácter no solo de puerto comercial internacional, sino también de plaza fuerte y sede de un proyecto político de base territorial, convirtiéndose a lo largo de esta centuria en una ciudad-estado fenicia occidental. Algunos de los rasgos que definirán la nueva posición emergente de la ciudad quedan evidenciados en el solar del Rectorado, tales como las obras de aterrazamiento o fortificación que se documentaron en la excavación efectuada aquí entre 1998 y 2002. Independientemente de su función, estas estructuras se vinculan a un asentamiento permanente y no a una ocupación temporal, de la misma manera que vemos también en los niveles fundacionales de los cercanos palacio de Buenavista y solar de calle Císter 3 - San Agustín 4 (Arancibia y Escalante 2010: 3638, Escalante et al. 2012: 87, García Alfonso 2018b: 36).

Igualmente, la presencia de esta ánfora ática de tipo SOS viene a señalar que la nueva fundación está recibiendo productos importados de cierta relevancia. Por ello, tanto el ánfora SOS como el citado dino quiota son unos de los pocos elementos que nos hablan de este posible papel que fue adquiriendo progresivamente el recién fundado asentamiento como nuevo destino del comercio de productos griegos a lo largo de la segunda mitad del siglo VII. A partir de c. 600 a.C. tenemos en la bahía de Málaga una mayor presencia de ánforas áticas, ya sean de tipo SOS o à la brosse, mientras desciende rápidamente su presencia en Toscanos (v. fig. 6). Así, en la propia ciudad de Málaga se han publicado diversos fragmentos: cinco en la zona alta del teatro romano (Gran-Aymerich 1991: 74, fig. 51, n. 4-8) y cuatro más en el palacio de Buenavista (Cisneros et al. 2000: 198 y 200). También se cita la presencia de este tipo anfórico en el solar de calle Císter 3 - San Agustín 4, pero no se menciona el número de fragmentos (Arancibia y Escalante 2010: 3644). Igualmente, también conocemos dos ejemplares más de ánfora ática en el Cerro del Villar durante los momentos iniciales del siglo VI a.C., poco antes del abandono de este asentamiento (Cabrera 1994b: 108). Desgraciadamente, por el momento, en todos los casos se trata de un material muy fragmentario, de pequeño tamaño, frecuentemente 
amorfo y mal conservado, por lo que es imposible en bastantes casos señalar si estamos ante ejemplares SOS o à la brosse, así como hacer una cuantificación del número mínimo de individuos.

En cualquier caso, la presencia del material anfórico arriba citado, así como el resto de cerámicas griegas que encontramos en la ciudad de Málaga (García Alfonso 2018a: 466-469) nos viene a confirmar que, desde comienzos del siglo VI a.C., este núcleo se había convertido en el principal destino de estos productos, en detrimento del papel que jugó Toscanos en la centuria anterior. En este sentido, el ejemplar de ánfora ática tipo SOS del solar del Rectorado, además de su papel de indicador cronológico para fechar los primeros momentos de ocupación del sitio, es también un indicador del cambio en los circuitos comerciales. Por ello, el desvío de las redes que suministraban productos griegos desde la desembocadura del Vélez a la del Guadalmedina se inició ya a lo largo de la segunda mitad del siglo VII, tímidamente al principio, acelerándose considerablemente a partir de c. 600 a.C., hasta su concentración total en la Málaga fenicia, convertida ya en esos momentos en una ciudad-estado.

\section{Agradecimientos}

Agradezco a José Suárez Padilla, Joan Ramon Torres, Bartolomé Mora Serrano, Leticia Salvago Soto y Cristina Chacón Mohedano su amabilidad al invitarme a participar en el estudio de los materiales del solar del Rectorado de la Universidad de Málaga con la presente contribución. Igualmente, quiero dar las gracias a Francisco Martínez Sevilla (Departamento de Prehistoria y Arqueología, Universidad de Granada) por su colaboración en las observaciones de la pieza con la lupa binocular.

Esta publicación forma parte de los resultados del proyecto de investigación I+D (HAR2015-68669-P) financiado por el Gobierno de España.

\section{BIBLIOGRAFÍA}

Albanese, R. M. (1996): “Appunti sulla distribuzione delle anfore commerciali nella Sicilia arcaica". Kokalos 42: 91-137.

Aquilué, X.; Castanyer, P.; Santos, M. y Tremoleda, J. (2000): "Les ceràmiques gregues arcaiques de la Palaià Polis d'Emporion", en P. Cabrera y M. Santos (coords.), Ceràmiques jònies d'època arcaica: centres de producción i comercialització al
Mediterrani Occidental, Actes de la Taula Rodona. Monografies Emporitanes 11: 285-338. Ampurias (1999), Barcelona, Generalitat de Catalunya.

Arancibia, A. y Escalante, M. del M. (2006): “Génesis y consolidación de la ciudad de Malaka", en Memoria arqueológica del Museo Picasso Málaga desde los orígenes hasta el siglo $V d$. C.: 41-78. Málaga, Museo Picasso Málaga.

Arancibia, A. y Escalante, M. del M. (2010): “Aportaciones a la arqueología urbana de Málaga, de la Málaga fenicia a la Málaga bizantina a través de los resultados de la excavación de C/. Císter 3 - San Agustín 4". Anuario Arqueológico de Andalucía 2006: 3636-3656.

Aubet, M. E. (2009): Tiro y las colonias fenicias de Occidente, $3^{\mathrm{a}}$ ed. actualizada y ampliada. Barcelona, Bellaterra.

Bron, G. (2011): "Les amphores du dépôt du Secteur 4 de l'Incoronata (Basilicate): essai tipo-chronologique et contextuel d'une clase céramique du VIIe siècle av. J.-C.”. Mélanges de l'École Française de Rome - Antiquité 123 (2): 467-504. https://doi. org/10.4000/mefra.441.

Buxó, R. (1997): Arqueología de las plantas. La explotación económica de las semillas y los frutos en el marco mediterráneo de la Península Ibérica. Barcelona, Crítica.

Buxó, R. y Piqué, R. (2008): Arqueobotánica. Los usos de las plantas en la Península Ibérica. Barcelona, Ariel.

Cabrera, P. (1989): "El comercio foceo en Huelva: cronología y fisionomía”, en J. Fernández Jurado (ed.), Tartessos y Huelva, Huelva Arqueológica 10-11, vol. III: 41-100. Huelva, Diputación Provincial de Huelva.

Cabrera, P. (1994a): "Comercio internacional mediterráneo en el siglo VIII a.C.”. Archivo Español de Arqueología 67: 15-30. https://doi.org/10.3989/ aespa.1994.v67.391.

Cabrera, P. (1994b): "Importaciones griegas arcaicas del Cerro del Villar (Guadalhorce, Málaga)", en P. Cabrera, R. Olmos y E. Sanmartí (coords.), Iberos y griegos. Lecturas desde la diversidad, Simposio Internacional. Huelva Arqueológica 13, vol. I: $97-$ 121. Ampurias (1991), Huelva, Diputación Provincial de Huelva.

Cabrera, P. (1995): “Cerámicas griegas en Tartessos: su significado en la costa meridional de la Península desde Málaga a Huelva", en Tartessos, 25 años después, 1968-1993. Actas del Congreso Conmemorativo del V Symposium Internacional de 
Prehistoria Peninsular: 387-399. Jerez de la Frontera (1993), Jerez de la Frontera, Ayuntamiento de Jerez de la Frontera.

Cabrera, P. (2003): “Cerámicas griegas y comercio fenicio en el Mediterráneo occidental", en B. Costa y J. H. Fernández (eds.), Contactos en el extremo de la oikouméne. Los griegos en Occidente y sus relaciones con los fenicios. XVII Jornadas de Arqueología Fenicio Púnica. Treballs del Museu Arqueològic d'Eivissa i Formentera 51: 61-86. Ibiza (2002), Ibiza, Govern de les Illes Balears, Conselleria d'Educació i Cultura.

Castanyer, P.; Santos, M. y Tremoleda, J. (1999): "L'assentament d'època arcaica: fase III", en X. Aquilué (dir.), Intervencions arqueològiques a Sant Martí d'Empúries (1994-1996). De l'assentament precolonial a l'Empúries actual. Monografies Emporitanes 9: 217-330. Gerona, Generalitat de Catalunya.

Chacón, C. (1999): Informe preliminar del sondeo arqueológico en el antiguo edificio de Correos sito en calle Cervantes, $s / n$ y futura sede del Rectorado de la Universidad de Málaga. Archivo de la Delegación Territorial de Cultura y Patrimonio Histórico en Málaga, Junta de Andalucía, expte. Arqueología n. ${ }^{\circ}$ 54/1998.

Chacón, C. y Salvago, L. (2005): “Actividad arqueológica en la antigua Casa de Correos y Telégrafos. Integración de los restos excavados en la sede del Rectorado de la Universidad de Málaga (19982002)". Anuario Arqueológico de Andalucía 2002, vol. III (2): 18-28.

Cisneros, M. I.; Suárez, J.; Mayorga, J. y Escalante, M. M. (2000): "Cerámicas griegas arcaicas en la bahía de Málaga”, en P. Cabrera y M. Santos (eds.), Ceràmiques jònies d'època arcaica: centres de producció i comercialització al Mediterrani occidental, Actes de la Taula Rodona. Monografies Emporitanes 11: 189-205. Ampurias (1999), Barcelona, Generalitat de Catalunya.

Cook, R. M. y Dupont, P. (1998): East Greek Pottery. Londres - Nueva York, Routledge.

Ciuccarelli, R. (2013): "La tombe 4 de Monte Abatone", en L. Streiff-Rivail (coord.), Les étrusques et la Méditerranée. La cité de Cerveteri. Catálogo de exposición Louvre Lens, 2013-2014: 116-119. París, Musée du Louvre y Somogy, Editions d'Art.

Di Sandro, N. (1986): Le anfore arcaiche dallo scarico Gosetti, Pithecusa. Cahiers du Centre Jean Bérard 13. Nápoles, Centre Jean Bérard.

Docter, R. F. (1997): Archaische Amphoren aus Karthago und Toscanos. Fundspektrum und Formenwicklung.
Ein Beitrag zur Phönizischen Wirtschaftgeschichte. Tesis Doctoral, Universidad de Amsterdam. Inédita.

Docter, R. F. (2000): "East Greek Fine Wares and Transport Amphorae of the 8th - 5th Century BC from Carthage and Toscanos", en P. Cabrera y M. Santos (eds.), Ceràmiques jònies d'època arcaica: centres de producció i comercialització al Mediterrani occidental, Actes de la Taula Rodona. Monografíes Emporitanes 11: 63-88. Ampurias (1999), Barcelona, Generalitat de Catalunya.

Domínguez Monedero, A. J. (2000): “Los mecanismos del emporion en la práctica comercial de los foceos y otros griegos del Este", en P. Cabrera y M. Santos (eds.), Ceràmiques jònies d'època arcaica: centres de producció i comercialització al Mediterrani occidental, Actes de la Taula Rodona. Monografíes Emporitanes 11: 27-45. Ampurias (1999), Barcelona, Generalitat de Catalunya.

Domínguez Monedero, A. J. (2001): Solón de Atenas. Barcelona, Crítica.

Dominguez Monedero, A. J. y Sánchez, C. (2001): Greek Pottery from the Iberian Peninsula. Archaic and Classical Periods. Leiden-Boston-Colonia, Brill.

Eitam, D. (1996): “The Olive Oil Industry at Tel Miqne-Ekron in the Late Iron Age", en D. Eitam y M. Heltzer (eds.), Olive Oil in Antiquity. Israel and Neighbouring Countries from the Neolithic to the Early Arab Period. History of the Near East Studies 7: 167-196. Padua, Sargon SRL.

Gailledrat, É y Rouillard, P. (2007): “Les amphores", en P. Rouillard, É. Gailledrat, y F. Sala (eds.), L'établissement protohistorique de La Fonteta (fin $V_{I I I}{ }^{\mathrm{e}}$ - fin VI $^{\mathrm{e}}$ siècle av. J.-C.): 225-232. Madrid, Casa de Velázquez.

García Alfonso, E. (2015): “Toscanos y la importación del aceite griego en la costa malagueña durante el periodo fenicio arcaico". Mainake 35: 137-156.

García Alfonso, E. (2018a): "Mercados y alianzas en el Occidente fenicio: cinco siglos de comercio griego en Málaga”, en M. Botto (ed.), De Huelva a Malaka. Los fenicios en Andalucía a la luz de los descubrimientos más recientes. Collezioni di Studi Fenici 48: 445-498. Roma, Consiglio Nazionale delle Ricerche, Istituto di Studi sul Mediterraneo Antico.

García Alfonso, E. (2018b): "Málaka en los siglos VIIVI a.C. Los orígenes de una ciudad-estado fenicia occidental", en D. García González, S. López Chamizo y E. García Alfonso (eds.), La Tumba del Guerrero. Un enterramiento excepcional en la Málaga fenicia del siglo VI a.C.: 25-74. Sevilla, Junta de Andalucía, Consejería de Cultura. 
García Martín, J. M. (2011): “Las cerámicas griegas”, en A. González Prats (coord. y ed.), La Fonteta. Excavaciones de 1996-2002 en la colonia fenicia de la actual desembocadura del río Segura (Guardamar del Segura, Alicante), vol. 1: 531-560. Alicante, Universidad de Alicante - Centro de Estudios Fenicios y Púnicos, Universidad Complutense de Madrid.

Gitin, S. (1998): "Philistia in Transition: the Tenth Century BCE", en S. Gitin, A. Mazar y E. Stern, Mediterranean Peoples in Transition. Thirteen to Early Ten Centuries BCE: 162-183. Jerusalén, Israel Exploration Society.

Gran-Aymerich, J. (1991): Malaga phénicienne et punique. Recherches franco-espagnoles 1981-1988. París, Editions Recherche sur les Civilisations.

Gras, M. (1987): “Amphores commerciales et histoire archaïque". Dialoghi di Archeologia 5: 41-50.

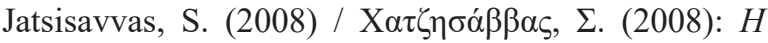

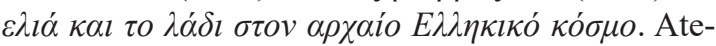
nas, Fundación Cultural Grupo Banco de El Pireo.

Johnston, A. y Jones, R. D. (1978): "The SOS Amphora". The Annual of the British School at Athens 73: 103-141.

Koehler, C. G. (1981): “Corinthian Developments in the Study of Trade in the Fifth Century". Hesperia 50 (4): 449-458.

Koparal, E.; İplikçi, E. y Savaş Bakir, A. (2010): “Klazomenai Olive Oil Plant: Dating, Reconstruction and Contemporany Use of it", en U. Aydinoğlu y A.K. Şenol (eds.), Olive Oil and Wine Production in Anatolia during Antiquity, Symposium Proceedings: 319-335. Mersin (2008), Estambul, Research Center of Cilician Archaeology.

Lemos, A. A. (1991): Archaic Pottery of Chios. The Decorated Styles. Oxford, Oxford University Committee for Archaeology.

López Pardo, F. y Mederos, A. (2008): La factoría fenicia de la isla de Mogador y los pueblos del Atlas. Santa Cruz de Tenerife, Organismo Autonómo de Museos y Centros - Cabildo de Tenerife.

Martín Ruiz, J. A. (2013): “El aceite en la Protohistoria del sur de la Península Ibérica". Florentia Iliberritana 24: 111-125.

Miró, J. (1989): “Ánforas arcaicas en el litoral catalán. Un estudio acerca de las primeras importaciones de vino en Cataluña (625-500 a.C.)". Archivo Español de Arqueología 62: 21-70.

Niemeyer, H. G. (1980): “A la búsqueda de Mainake: el conflicto entre los testimonios arqueológicos y escritos". Habis 10-11: 279-302. http://10.12795/ Habis.1979-80.i10-11.21.

Niemeyer, H. G. (1986): "El yacimiento fenicio de Toscanos: urbanística y función”, en G. del Olmo y M. E. Aubet (eds.), Los fenicios en la Península Ibérica, vol. I: 109-126. Sabadell, Ausa.

Pardo, C. A. (2015): Economía y sociedad rural fenicia en el Mediterráneo occidental. Sevilla, Universidad de Sevilla.

Pratt, C. E. (2015): "The «SOS» Amphora: an Update". Annual of the British School at Athens 110: 213-246. http://dx.doi.org/10.1017/S0068245414000240.

Rizzo, M. A. (1990): Le anfore da transporto e il commercio etrusco arcaico, vol. I. Complessi tombali dell'Etruria meridionale. Catálogo de la Exposición, Museo Nazionale della Villa Giulia, Roma (1993). Roma, De Luca Edizioni d'Arte.

Ramon, J. (1983): "Cuatro elementos cerámicos arcaicos de importación encontrados en Ibiza". Informació Arqueolòica 40: 111-120.

Rouillard, P. (1991): Les Grecs et la Péninsule Ibérique du VIII au IV siècle avant Jésus-Christ. Burdeos, Centre Pierre Paris.

Rouillard, P. (2007): "La céramique grecque", en P. Rouillard, É. Gailledrat y F. Sala (eds.), L'établissement protohistorique de La Fonteta (fin VIII - fin VI siècle av. J.-C.): 190. Madrid, Casa de Velázquez.

Sacchetti, F. (2012): Les amphores grecques dans le nord de l'Italie. Échanges commerciaux entre les Apennins at les Alpes aux époques archaïque et classique. Aix-en-Provence, Centre Camille Jullian - Errance.

Sourisseau, J.-C. (2006): "Les Amphores commerciales de la nécropole de Rifriscolaro à Camarine", en P. Pelagatti, G. di Stefano y L. de Lachenal (eds.), Camarina. 2600 anni dopo la fondazione. Nuovi studi sulla città e sul territorio, Atti del Convegno Internazionale: 129-147. Ragusa (2002 y 2003), Roma, Istituto Poligrafico e Zecca dello Stato.

Schubart, H. (1984): "Morro de Mezquitilla. Informe preliminar sobre la campaña de excavaciones de 1981 en el Morro de Mezquitilla cerca de la desembocadura del río Algarrobo". Noticiario Arqueológico Hispánico 19: 85-101.

Suárez, J.; Ramon, J., Mora, B.; Salvago, L. y Chacón, C. (2020): "La cronología fundacional de la Malaka fenicia: investigaciones en el solar del Rectorado de la Universidad de Málaga", Spal 29.1: 41-77. http:// dx.doi.org/10.12795/spal.2020.i29.02. 
Torelli, M. (2007): La strategie di Kleitias. Composizione e programma figurativo del vaso François. Milán, Electa.

Whitbread, I. K. (1995): Greek Transport Amphorae. A Petrological and Archaeological Study. Exeter, The British School at Athens.
Vegas, M. (1999): "El ánfora griega del estrato V", en M. E. Aubet, P. Carmona, E. Curià, A. Delgado, A. Fernández Cantos y M. Párraga (eds.), Cerro del Villar-I. El asentamiento fenicio en la desembocadura del río Guadalhorce y su interacción con el hinterland: 136. Sevilla, Consejería de Cultura, Junta de Andalucía. 